\title{
Pars Plana Vitrectomy vs Combined Pars Plana Vitrectomy-Scleral Buckle for Primary Repair of Pediatrics Retinal Detachment
}

\author{
Abdulaziz A Al Taisan (D) ${ }^{1,2}$ \\ Abdulaziz A Alshamrani (iD ${ }^{\prime}$ \\ Abdullah T AlZahrani ${ }^{3}$ \\ Abdulelah A Al-Abdullah' \\ 'Vitreoretinal Division, King Khaled Eye \\ Specialist Hospital, Riyadh, Saudi Arabia; \\ ${ }^{2}$ Surgery Department, College of \\ Medicine, King Faisal University, Al-Ahsa, \\ Saudi Arabia; ${ }^{3}$ Glaucoma Division, King \\ Khaled Eye Specialist Hospital, Riyadh, \\ Saudi Arabia
}

\begin{abstract}
Purpose: To evaluate the outcome of pars plana vitrectomy (PPV) and combined pars plana vitrectomy with scleral buckle (PPV-SB) in the primary pediatrics rhegmatogenous retinal detachment repair.

Design: A retrospective cohort study.

Methods: A retrospective study was conducted in patients under 18 years of age, who presented with rhegmatogenous retinal detachment at King Khaled Eye Specialist Hospital between January 2014 and October 2018. Primary measurable outcomes were single surgery success rate (SSSR) and rate of postoperative complications.

Results: A total of 122 eyes of 117 patients were included in the study; 80 eyes in PPV group and 42 eyes in PPV-SB group. Mean follow-up period after surgery was 18.2 months \pm 11 months. SSSR was $76.3 \%(\mathrm{n}=61)$ and $66.7 \%(\mathrm{n}=28)$ for PPV and PPV-SB, respectively. No statistically significant difference was found between the two methods of RRD repair in single surgery success rate with an OR of $1.3(P=0.45)$. Complication rates were comparable in both groups in the last follow-up.

Conclusion: In this series, PPV and PPV-SB have comparable results in regard to anatomical success and rate of postoperative complications. More complicated cases were selected to undergo PPV-SB upon surgeons' preference.
\end{abstract}

Keywords: retinal detachment, pediatrics, pars plana vitrectomy, scleral buckle

\section{Introduction}

Pediatric retinal detachment accounts for up to $5.9 \%$ of all rhegmatogenous retinal detachments (RRD). ${ }^{1-6}$ Many etiological factors have been reported as a cause of $\mathrm{RRD}$ in this age group including congenital anomalies, trauma, myopia, ocular surgeries including laser treatment and cryotherapy, and family history. ${ }^{7,8}$ In addition, many ocular and systemic conditions have been associated with RRD like Marfan syndrome, Stickler syndrome, congenital retinoschisis, retinopathy of prematurity and morning glory syndrome. ${ }^{8-14}$

The low success rate in repairing RRD in the pediatric age group stems from several reasons. One of them is the fact that trauma accounts for up to $50 \%$ of RRDs in the pediatric age group ${ }^{15-17}$ it is understandable that the overall success rate would be less than that in adults. Furthermore, late presentation, anatomical features of the pediatric eyes, proliferative vitreoretinopathy, difficult vitreous separation, and the difficulty in maintaining a proper positioning in the postoperative period might lead to a lower success rate. ${ }^{18}$
Correspondence: Abdulelah A Al-Abdullah Vitreoretinal Division, King Khalid Eye Specialist Hospital, P.O. Box 719I, Riyadh, I 1462, Saudi Arabia

Tel +966 I | 482 I 234 Ext. 2655

Email aaabdullah@kkesh.med.sa 
Several series of pediatric retinal detachment have been reported with variable single surgery success rate (SSSR) ranging from 25 to $96 \%$ with limited data on comparing one procedure to the other. ${ }^{19-21}$ Hence the importance of evaluating the optimal surgical intervention with regard to outcome and complications is evident.

In this study, we are evaluating the outcomes of primary PPV vs SB-PPV in pediatric RRDs.

\section{Methods}

The study was carried at King Khaled Eye Specialist Hospital in Riyadh, Saudi Arabia. After approval from the institutional review board/ethics committee, we performed a retrospective analysis of all patients who underwent RRD repair between January 2014 and October 2018 in accordance with the Declaration of Helsinki. Patients' informed consent was waived due to the retrospective nature of the study. Patients' data confidentiality was maintained throughout the study. Inclusion criteria were patients who underwent repair of primary RRD under the age of 18 years with a minimum follow-up period of 12 months. Exclusion criteria were previous retinal surgery, previous pneumatic retinopexy, detachment related to intraocular infections or tumors and other causes of tractional or exudative retinal detachment.

A thorough chart review was done including demographic data, onset of the detachment (acute RRD defined as retinal detachment of less than one-month duration per history) and examination findings at the time of retinal detachment which included best corrected visual acuity, intraocular pressure, extent of detachment, macular involvement, number and type of breaks, involved quadrants). Visual acuity (VA) assessment was done using the Snellen chart or Sheridan Gardiner chart, as appropriate. For the purpose of analysis visual acuity was categorized into three groups: $20 / 20$ to $20 /$ $40,20 / 50$ to $20 / 200$, and less than 20/200)

Then operative notes were reviewed to obtain intraoperative findings, type of surgery, type of tamponade, dye used, ILM peel, laser vs cryotherapy. Postoperative follow-up visits findings were obtained at six, 12 months, and last follow-up visit to include retinal reattachment, best corrected visual acuity and development of postoperative complications including, but not limited to: cataract formation, elevated intraocular pressure (defined as IOP higher than $21 \mathrm{mmHg}$ by applanation tonometry), proliferative vitreoretinopathy, epiretinal membrane formation.

All patients underwent 23-gauge pars plana vitrectomy with or without the addition of an encircling band.
Different intraoperative tamponade agents were used. The study included surgeries done by multiple surgeons, including certified vitreoretinal surgeons and in-training fellows under direct supervision. Postoperative regiment was similar in both groups which included the use of topical antibiotics, mydriatic agents and topical steroids which was tapered according to the degree of postoperative inflammation.

Statistical analysis was done using SPSS 25.0, qualitative variables were represented as frequencies and percentages. Odds ratio, relative risk, chi-squared and Fisher's exact test were used when appropriate.

\section{Results}

A total of 122 eyes of 117 patients were included in the study. Eighty eyes of 77 patients underwent pars plana vitrectomy alone (PPV group) and 42 eyes of 40 patients underwent PPV with scleral buckle (PPV-SB group). In

Table I Baseline Characteristics of Our Cohort of II7 Patients (I 22 Eyes)

\begin{tabular}{|c|c|c|c|c|}
\hline & & $\begin{array}{l}P P V^{a} \\
(n=80)\end{array}$ & $\begin{array}{c}\text { PPV-SB }^{b} \\
(n=42)\end{array}$ & $P$-value \\
\hline $\begin{array}{l}\text { Age } \\
\text { (years) }\end{array}$ & Mean (SD) & $\begin{array}{c}10.2(5.3) \\
\text { n (\%) }\end{array}$ & $\begin{array}{c}10.9(4.8) \\
n(\%)\end{array}$ & 0.633 \\
\hline Gender & $\begin{array}{l}\text { Male } \\
\text { Female }\end{array}$ & $\begin{array}{c}56(70) \\
24(31.2)\end{array}$ & $\begin{array}{c}30(71.4) \\
12(30)\end{array}$ & 0.869 \\
\hline Onset & $\begin{array}{l}\text { Acute } \\
\text { Chronic }\end{array}$ & $\begin{array}{l}58(72.5) \\
22(27.5)\end{array}$ & $\begin{array}{l}\text { II (26.2) } \\
3 \text { I (73.8) }\end{array}$ & $<0.001$ \\
\hline Macula & $\begin{array}{l}\text { On } \\
\text { Off }\end{array}$ & $\begin{array}{c}6(7.5) \\
74(92.5)\end{array}$ & $\begin{array}{c}2(4.8) \\
40(95.2)\end{array}$ & 0.713 \\
\hline $\begin{array}{l}\text { Eye } \\
\text { involved }\end{array}$ & $\begin{array}{l}\text { OD } \\
\text { OS }\end{array}$ & $\begin{array}{l}38(47.5) \\
42(52.5)\end{array}$ & $\begin{array}{l}18(42.9) \\
24(57.1)\end{array}$ & 0.625 \\
\hline Etiology & $\begin{array}{l}\text { Spontaneous } \\
\text { Traumatic } \\
\text { High myopia } \\
\text { Post surgery } \\
\text { Syndrome } \\
\text { Marfan } \\
\text { Knoblock } \\
\text { Down } \\
\text { Albinism } \\
\text { Stickler } \\
\text { Neurofibromatosis } \\
\text { Microphthalmos } \\
\text { Pierson }\end{array}$ & $\begin{array}{c}5(6.3) \\
36(45) \\
10(12.5) \\
22(27.5) \\
7(8.8) \\
2 \\
2 \\
0 \\
1 \\
1 \\
1 \\
0 \\
0\end{array}$ & $\begin{array}{c}3(7.1) \\
14(33.3) \\
8(19) \\
5(11.9) \\
12(28.6) \\
2 \\
1 \\
2 \\
0 \\
4 \\
0 \\
1 \\
1\end{array}$ & $\begin{array}{c}0.7 \\
0.25 \\
0.33 \\
0.05 \\
0.004\end{array}$ \\
\hline
\end{tabular}

Notes: ${ }^{\text {aPars }}$ plana vitrectomy. ${ }^{\mathrm{b}}$ Combined pars plana vitrectomy with scleral buckle. 
the PPV group the mean follow-up period was 19.2 months \pm 11 months, while it was 18 months \pm 12 months in PPV-SB group $(P=0.44)$. The mean age of the patients was $10.2 \pm 5.3$ years vs $10.9 \pm 4.8$ years in the PPV group vs PPV-SB group respectively ( $P=0.63$ ).

The main cause of detachment in our patients was trauma which represented $45 \%$ in the PPV group vs $33.3 \%$ in the PPV-SB group $P=0.25$. Other causes of detachment include post surgeries, high myopia, syndromic detachment and spontaneous detachment. Variety of syndromes were associated with RRD in our study as illustrated in Table 1.

Acute-onset RRD was found in $72.5 \%$ of the eyes in PPV group while it was found on only $26.2 \%$ of the eyes in SB-PPV group $(P<0.001)$. We noticed that patients with PVR had been operated on with PPV-SB more often
(26.3\% in the PPV group vs $54.8 \%$ in the PPV-SB group, $P=0.002$ ). Phakic patients were more in the PPVSB group, however this was statistically insignificant (92.9\% in the PPV-SB group vs $86.3 \%$ in the PPV group, $P=0.28$ ) (Table 2).

Regarding the characteristics of the detachment, there was no statistically significant difference between the two groups in the number of breaks, number of quadrants involved, rates of retinectomy, intentional retinotomy and the tamponade agents used. However, more cases with inferior breaks were in the PPV-SB group; 36\% compared to $23 \%$ in the PPV group $(P=0.04)$.

Single surgery success rate (SSSR) was $76.3 \%(n=61)$ and $66.7 \%(\mathrm{n}=28)(P=0.45)$ for PPV and PPV-SB respectively. Among the 33 cases that were not successful with the first surgery, nine cases had incomplete vitreous

Table 2 Intraoperative Findings for Both Groups PPV and PPV/SB

\begin{tabular}{|c|c|c|c|c|}
\hline & & PPV n (\%) & PPV/SB n (\%) & $P$-value \\
\hline Intraoperative breaks & $\begin{array}{c}\text { Single } \\
\text { Multiple } \\
\text { GRT } \\
\text { No breaks seen }\end{array}$ & $\begin{array}{c}26(32.5) \\
30(37.5) \\
12(15) \\
12(15)\end{array}$ & $\begin{array}{c}10(23.8) \\
16(38.1) \\
8(19) \\
8(19)\end{array}$ & 0.739 \\
\hline Location of breaks & $\begin{array}{c}\text { Inferior } \\
\text { Noninferior }\end{array}$ & $\begin{array}{l}18(23) \\
62(77)\end{array}$ & $\begin{array}{l}15(36) \\
27(64)\end{array}$ & 0.036 \\
\hline Quadrant involved & $\begin{array}{c}\text { Total } \\
\text { Sub-total }\end{array}$ & $\begin{array}{l}45(56.3) \\
35(43.8)\end{array}$ & $\begin{array}{l}27(64.3) \\
15(35.7)\end{array}$ & 0.391 \\
\hline Lens status & $\begin{array}{c}\text { Aphakia/pseudophakia } \\
\text { Phakia }\end{array}$ & $\begin{array}{l}\text { II (13.8) } \\
69(86.3)\end{array}$ & $\begin{array}{c}3(7.1) \\
39(92.9)\end{array}$ & 0.28 \\
\hline FTMH & $\begin{array}{l}\text { Yes } \\
\text { No }\end{array}$ & $\begin{array}{c}5(6.3) \\
75(93.8)\end{array}$ & $\begin{array}{c}3(7.1) \\
39(92.9)\end{array}$ & 0.850 \\
\hline Presence of PVR & $\begin{array}{l}\text { Absent } \\
\text { Present }\end{array}$ & $\begin{array}{l}59(73.8) \\
21(26.3)\end{array}$ & $\begin{array}{l}19(45.2) \\
23(54.8)\end{array}$ & 0.002 \\
\hline Retinectomy & $\begin{array}{l}\text { Yes } \\
\text { No }\end{array}$ & $\begin{array}{l}10(12.5) \\
70(87.5)\end{array}$ & $\begin{array}{c}4(9.5) \\
38(90.5)\end{array}$ & 0.769 \\
\hline Intentional retinotomy & $\begin{array}{l}\text { Yes } \\
\text { No }\end{array}$ & $\begin{array}{l}19(23.8) \\
61(76.3)\end{array}$ & $\begin{array}{l}10(23.8) \\
32(76.2)\end{array}$ & 0.994 \\
\hline Dye used & $\begin{array}{c}\text { Brilliant blue (with or without triamcinolone) } \\
\text { Triamcinolone alone } \\
\text { No dye }\end{array}$ & $\begin{array}{l}16(20) \\
26(32.5) \\
38(47.5)\end{array}$ & $\begin{array}{c}4(9.5) \\
21(50) \\
17(40.5)\end{array}$ & \\
\hline Tamponade agents & $\begin{array}{c}\text { Gas }\left(\mathrm{SF}_{6} \text { or } \mathrm{C}_{3} \mathrm{~F}_{8}\right) \\
\text { Silicone oil }\end{array}$ & $\begin{array}{l}9(11.3) \\
71(88.8)\end{array}$ & $\begin{array}{c}2(4.8) \\
40(95.2)\end{array}$ & 0.670 \\
\hline Surgeon & $\begin{array}{c}\text { Fellow } \\
\text { Consultant }\end{array}$ & $\begin{array}{l}14(17.5) \\
66(82.5)\end{array}$ & $\begin{array}{c}7(16.7) \\
35(83.3)\end{array}$ & 0.908 \\
\hline
\end{tabular}

Abbreviations: GRT, giant retinal tear; $F T M H$, full-thickness macular hole; $P V R$, proliferate vitreoretinopathy, $\mathrm{SF}_{6}$, sulfur hexafluoride; $\mathrm{C}_{3} \mathrm{~F}_{8}$ perfluoropropane. 
separation (27\%); four in the PPV group and five in the PPV-SB group. There was no significant difference in SSSR between the two groups, PPV and PPV-SB, when looking into the eyes based on the chronicity (acute vs chronic detachment), the etiology and the status of PVR (present vs absent) (Table 3). Further analysis was done for cases with inferior breaks which showed comparable results in both groups; SSSR of $75 \%$ in PPV group and $73 \%$ in PPV-SB group.

After the second surgery the success rate was $93.8 \%$ in the PPV group vs $92.7 \%$ in the PPV-SB group. Table 4 shows the number of surgeries needed in each group.

Overall, $82.5 \%$ of PPV and $83.3 \%$ of PPV-SB cases were done by vitreoretinal consultants. In contrast, $97.7 \%$ of cases with PVR were done by consultants (either PPV or PPV-SB) and $74 \%$ of cases without PVR were done by consultants.

Preoperative VA was measurable in $82.5 \%$ of patients in both the PPV and the PPV-SB groups. In the PPV group, $20 \%$ of patients had VA better than 20/200, which increased to $33.8 \%$ at the last follow-up visit $(P=0.019)$. While in the PPV-SB group: $9.5 \%$ of patients had VA better than $20 / 200$ at presentation which increased to $40.5 \%$ at the last follow-up $(P=0.004)$. No statistical significance was found in the postoperative VA between consultants and fellows (Table 5).

Table 3 Single Surgery Success Rates According to Chronicity, Status of PVR and Etiology

\begin{tabular}{|c|c|c|c|}
\hline & PPV & PPV/SB & \\
\hline & $\begin{array}{l}\text { SSSR/Total } \\
\text { (\%) }\end{array}$ & $\begin{array}{l}\text { SSSR/Total } \\
\text { (\%) }\end{array}$ & $P$-value \\
\hline Overall SSSR & $61 / 80(76.3)$ & $28 / 42(66.7)$ & 0.45 \\
\hline $\begin{array}{l}\text { Acute RRD } \\
\text { Chronic RRD }\end{array}$ & $\begin{array}{l}45 / 58(77.5) \\
16 / 22(72.7)\end{array}$ & $\begin{array}{l}7 / I I(63.6) \\
2 I / 3 \mid(67.6)\end{array}$ & 0.78 \\
\hline $\begin{array}{l}\text { PVR+ } \\
\text { PVR- }\end{array}$ & $\begin{array}{l}|7 / 2|(8 \mid) \\
44 / 59(74.6)\end{array}$ & $\begin{array}{l}18 / 23(78.3) \\
10 / 19(52.6)\end{array}$ & 0.99 \\
\hline $\begin{array}{l}\text { Spontaneous } \\
\text { RRD }\end{array}$ & $5 / 5(100)$ & $3 / 3(100)$ & 1.0 \\
\hline Traumatic & $26 / 36(72.2)$ & $9 / 14(64.3)$ & 0.73 \\
\hline High myopia & $8 / 10(80)$ & $5 / 8(62.5)$ & 0.61 \\
\hline Post surgery & I5/22 (61.3) & $3 / 5(60)$ & 0.99 \\
\hline Syndromatic & $7 / 7(100)$ & $8 / 12$ (66.7) & 0.25 \\
\hline
\end{tabular}

Abbreviations: PVR, proliferative vitreoretinopathy; SSSR, single surgery success rate. RRD, hegmatogenous retinal detachment.
Table 4 Number of Reattachment Surgeries and the Success Rate

\begin{tabular}{|l|c|c|}
\hline No. of Reattachment Surgeries & PPV $\mathbf{n}(\%)$ & PPV-SB n (\%) \\
\hline $\mathrm{I}$ & $6 \mathrm{I}(76.3)$ & $28(66.7)$ \\
2 & $14(17.5)$ & $1 \mathrm{I}(26)$ \\
3 & $2(4)$ & $3(7.1)$ \\
4 & $1(1.3)$ & 0 \\
\hline
\end{tabular}

The overall rate of postoperative complications at six months was $37 \%$ and was slightly higher in the PPV-SB group (42.9\%) in the six-month follow-up compared to the PPV group (33.8\%) with no statistically significant difference ( $P=0.322$ ). At the last follow-up visit (last follow-up was at a mean of two years \pm 11 months), the rate was almost equal in both groups; $31 \%$ for PPV-SB vs $32.5 \%$ for PPV $(P=0.0 .862)$ since some complications like cataract and epiretinal membranes were managed surgically. A full list of complications is demonstrated in Table 6 .

\section{Discussion}

This study is trying to address the role of PPV with or without SB in treating primary pediatric RRDs. PPV vs PPV-SB has been evaluated previously in adult RRD. However, to our knowledge a similar comparison in the pediatric age group was not studied before.

At the initial look of baseline characteristics of the eyes in both groups, we noticed significant differences at the distribution of eyes with acute RRD being more subjected to PPV alone. This indicates surgeon's preference toward PPV alone in cases of acute RRD. On the contrary, in

Table 5 Initial and Final BCVA in PPV and PPV-SB Groups

\begin{tabular}{|l|l|l|l|}
\hline & $\begin{array}{l}\text { Initial BCVA } \\
\text { n (\%) }\end{array}$ & $\begin{array}{l}\text { Final BCVA } \\
\text { n (\%) }\end{array}$ & P value \\
\hline PPV n=80 & & & \\
$20 / 20$ to $20 / 40$ & $3(3.8)$ & $6(7.5)$ & 0.019 \\
$24 / 40$ to 20/200 & $13(16.3)$ & $21(26.3)$ & \\
Less than 20/200 & $50(62.5)$ & $41(51.3)$ & \\
NA $^{\text {a }}$ & $14(17.5)$ & $12(15)$ & \\
\hline PPV-SB -42 & & $1(2.4)$ & 0.004 \\
$20 / 20$ to 20/40 & $1(2.4)$ & $16(38.1)$ & \\
$24 / 40$ to 20/200 & $3(7.1)$ & $17(40.5)$ & \\
Less than 20/200 & $30(71.4)$ & $8(19)$ & \\
NA & $14(17.5)$ & 0.27 & \\
P-value & 0.021 & & \\
\hline
\end{tabular}

Note: ${ }^{2}$ Not available or could not be obtained. Abbreviation: BCVA, best corrected visual acuity. 
Table 6 Rate of Postoperative Complications

\begin{tabular}{|c|c|c|c|c|c|c|}
\hline \multirow[t]{3}{*}{ Complications } & \multicolumn{2}{|c|}{6 Months } & \multicolumn{2}{|c|}{12 Months } & \multicolumn{2}{|c|}{ Last Visit } \\
\hline & PPV & PPV/SB & PPV & PPV/SB & PPV & PPV/SB \\
\hline & n (\%) & n (\%) & n (\%) & n (\%) & n (\%) & n (\%) \\
\hline ERM & $7(8.8)$ & $2(4.8)$ & $2(2.5)$ & $3(7.1)$ & $5(6.3)$ & $2(4.8)$ \\
\hline Macular hole & I (I.3) & 0 & I (I.3) & 0 & I (I.3) & 0 \\
\hline Cataract & $12(15)$ & II (26.2) & $7(8.8)$ & $9(21.4)$ & $6(7.5)$ & $5(11.9)$ \\
\hline High IOP & $7(8.8)$ & $2(4.8)$ & II (I3.8) & $6(14.3)$ & $12(15)$ & $5(11.9)$ \\
\hline PCO & 0 & I (2.4) & 0 & 0 & 0 & 0 \\
\hline Band keratopathy & I (I.3) & $2(4.8)$ & $2(2.5)$ & $3(7.1)$ & $3(3.8)$ & I (2.4) \\
\hline Phthisis bulbi & 0 & 0 & I (I.3) & 0 & I (I.3) & 0 \\
\hline PVR & $3(3.8)$ & $2(4.8)$ & I (I.3) & I (2.4) & 0 & 0 \\
\hline Total no. of eyes ${ }^{a}$ & $27(33.8)$ & $18(42.9)$ & 27 (33.8) & $19(45.2)$ & $26(32.5)$ & $13(3 \mid)$ \\
\hline
\end{tabular}

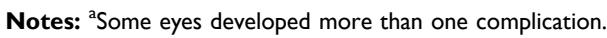

Abbreviations: ERM, epiretinal membrane; IOP, intraocular pressure; PCO, posterior capsular opacification; PVR, proliferative vitreoretinopathy.

chronic RRD, surgeons in our cohort tend to combine PPV with scleral buckle as chronic RRD was considered a complicated case. However, we analyze the success rate of acute and chronic RRD separately among the two groups PPV vs PPV-SB, which showed no significant difference $(P=0.78)$ in subgroups analysis table.

Primary success rate was slightly higher in the PPV group regardless of the etiology $(76.3 \%$ vs $66.7 \% ; P=0.45)$ with no statistical significance. However, with one additional surgery, the rates became comparable in both groups. In concordance with our result of the success rate, Al-Zaaidi ${ }^{21}$ reported SSSR in pediatric RRDs of $63 \%$ that increased to $80 \%$ with multiple reattachment surgeries, regardless of the type of primary surgery. In our series, however, we noticed a tendency toward doing PPV-SB in the presence of chronic RRD, presence of inferior breaks and presence of PVR. Chronic RRDs (73.8\%) underwent PPV-SB compared to $26.3 \%$ of chronic RRDs in PPV alone. The same was found in PVR where in the PPV-SB group 55\% of the eyes had preoperative PVR, compared to only $26.3 \%$ in the PPV group. However, the result of the subgroup analysis did not show significant difference between the two types of intervention PPV alone vs PPV-SB in the final outcome. Despite the fact that what has been labeled as chronic detachment and the presence of PVR might not be of equal stage. When looking in the location of breaks, eyes with inferior breaks were more in the PPV-SB group $(P=0.04)$. This coincides with a previous report by Orlin et $\mathrm{al}^{22}$ who reported similar surgeons' preference of performing PPV-SB in eyes with inferior breaks but they did not find a difference in the SSSR between both interventions; adding an encircling band did not increase the SSSR. Alexander et $\mathrm{al}^{23}$ proposed that supplementing PPV with a scleral buckle might increase the success rates in eyes with inferior breaks. In their study the SSSR was $95 \%$ at three months. However, there was no control group in their study and their results were compared to the previously published reports.

In our cohort, there was no statistically significant difference in regard to the lens status and the performed surgery with phakic eyes being more in the PPV-SB group. This is a point of controversy where some might prefer to place an encircling band in phakic patients due to the difficulty of properly shaving the peripheral vitreous while others prefer to place it in aphakic/ pseudophakic eyes due to the possibility of the presence of small undetectable breaks. ${ }^{22}$ Kinori et $\mathrm{al}^{24}$ and Orlin et $\mathrm{al}^{22}$ concluded that based on lens status, PPV-SB is comparable to PPV alone and Weichel et a ${ }^{25}$ PPV-SB and PPV have comparable results in pseudophakic eyes.

Pediatrics are considered at a higher risk of developing PVR compared to adults. ${ }^{26}$ When looking into the presence of PVR and its effect on SSSR, it was unexpectedly almost equal whether PVR is present or absent. Storey et $\mathrm{al}^{27}$ compared PPV alone vs PPV-SB in adult RRD at 
a high risk of PVR. They reported SSSR for PPV-SB to be $75 \%$ compared to $48 \%$ for PPV alone. Our unexpected results can be explained by the fact that $97.7 \%$ of PVR cases were operated on by experienced consultants compared to $74 \%$ of cases without PVR.; the more experienced the surgeon, the higher the success rate.

Visual outcome seems to be better in the PPV-SB group. However, the PPV-SB group had a significantly worse preoperative visual acuity and despite the anatomical success, visual improvement might not be a sequel. AlZaaidi $^{21}$ reported $50 \%$ lack of visual improvement and McElnea et al $^{17}$ reported $60 \%$ lack of visual improvement or even worsening visual acuity postoperatively. Furthermore, visual improvement in pediatrics RRD is related to other factors like amblyopia therapy, aphakia correction, reliable measure of visual evaluation in this age group.

Overall, the rate of postoperative complications in our cohort (37\%) was less than that previously reported by AlZaaidi $^{21}$ (64.5\%). Postoperative complications were slightly higher in the PPV-SB group; 43\% compared to $34 \%$ in the PPV group. However, this high rate was attributed mainly to cataract formation. Weichel et $\mathrm{al}^{25}$ reported postoperative complications of $32 \%$ in the PPVSB group and 19\% in the PPV group. However, their study included only noncomplex RRD and adult patients. The rate of PVR formation was comparable in both groups (at six months; $4.8 \%$ in the PPV-SB group and $3.8 \%$ in the PPV group) and comparable with other published studies in pseudophakic RRDs (6-17\%). ${ }^{25,28-30}$ One case underwent phthisis bulbi in the PPV group, the etiology of detachment in this eye was open globe injury. Open globe injury related detachments have poorer prognosis compared to other types of detachments. Sindal et $\mathrm{al}^{31}$ reported prethisis to be as high as $33 \%$ in open globe injuries and Sarrazin et $\mathrm{al}^{32}$ reported a reattachment rate in open globe injuries of $46 \%$.

The limitations of our study include its retrospective nature and the imbalance in the baseline characteristics. The later was overcome by comparing similar subgroups among both interventions separately. Furthermore, the procedure selection (either PPV vs PPV-SB) was performed based on each surgeon's own preference and experience.

In conclusion, PPV and PPV-SB has comparable results in regard to anatomical success and rate of postoperative complications despite the fact that complicated cases were more in the PPV-SB group which highlights that there might be a perceived value of scleral buckle with PPV among the surgeons in our cohort in complex pediatric RRDs.

\section{Acknowledgments}

Other Acknowledgments: Dr Abeer Ahmad, Biostatistician in Research Department, King Khaled Eye Specialist Hospital.

\section{Funding}

No funding was granted for this article.

\section{Disclosure}

The authors report no conflicts of interest in this work and no financial disclosures.

\section{References}

1. Akabane N, Yamamoto S, Tsukahara I, et al. Surgical outcomes in juvenile retinal detachment. Jpn J Ophthalmol. 2001;45(4):409-411. doi:10.1016/S0021-5155(01)00361-6

2. Butler TKH, Kiel AW, Orr GM. Anatomical and visual outcome of retinal detachment surgery in children. $\mathrm{Br} J$ Ophthalmol. 2001;85 (12):1437-1439. doi:10.1136/bjo.85.12.1437

3. Haimann MH, Burton TC, Brown CK. Epidemiology of retinal detachment. Arch Ophthalmol. 1982;100(2):289-292. doi:10.1001/ archopht.1982.01030030291012

4. Rosner M, Treister G, Belkin M. Epidemiology of retinal detachment in childhood and adolescence. J Pediatr Ophthalmol Strabismus. 1987;24(1):42-44.

5. Fivgas GD, Capone A Jr. Paediatric rhegmatogenous retinal detachment. Retina. 2001;21(2):101-106. doi:10.1097/00006982200104000-00001

6. Yokoyama T, Kato T, Minamoto A, et al. Characteristics and surgical outcomes of paediatric retinal detachment. Eye (Lond). 2004;18 (9):889-892. doi:10.1038/sj.eye.6701341

7. Go SL, Hoyng CB, Klaver CC. Genetic risk of rhegmatogenous retinal detachment: a Familial Aggregation Study. Arch Ophthalmol. 2005;123(9):1237-1241. doi:10.1001/archopht.123.9.1237

8. Greven CM, Tasman W. Rhegmatogenous retinal detachment following cryotherapy in retinopathy of prematurity. Arch Ophthalmol. 1989;107(7):1017-1018. doi:10.1001/archopht.1989.01070020079034

9. Park KH, Hwang JM, Choi MY, Yu YS, Chung H. Retinal detachment of regressed retinopathy of prematurity in children aged 2-15 years. Retina. 2004;24(3):368-375. doi:10.1097/00006982200406000-00006

10. Terasaki H, Hirose T. Late-onset retinal detachment associated with regressed retinopathy of prematurity. Jpn J Ophthalmol. 2003;47 (5):492-497. doi:10.1016/S0021-5155(03)00088-1

11. Jandeck C, Kellner U, Foerster MH. Late retinal detachment in patients born prematurely: outcome of primary pars plana vitrectomy. Arch Ophthalmol. 2004;122(1):61-64. doi:10.1001/ archopht.122.1.61

12. Stickler GB, Hughes W, Houchin P. Clinical features of hereditary progressive arthro ophthalmopathy (Stickler syndrome): a survey. Genet Med. 2001;3(3):192-196. doi:10.1097/00125817-20010500000008

13. Parke IDW. Stickler syndrome: clinical care and molecular genetics. Am J Ophthalmol. 2002;134(5):746-748. doi:10.1016/S00029394(02)01822-6 
14. Ang A, Poulson AV, Goodburn SF, Richards AJ, Scott JD, Snead MP. Retinal detachment and prophylaxis in type I stickler syndrome. Ophthalmology. 2008;115(1):164-168. doi:10.1016/j.ophtha.2007.03.059

15. Lee RWJ, Mayer EJ, Markham RH. The aetiology of paediatric rhegmatogenous retinal detachment: 15 years experience. Eye. 2008;22(5):636-640. doi:10.1038/sj.eye.6702724

16. Jalali S, Yorston D, Shah NJ, et al. Retinal detachment in South India - presentation and treatment outcomes. Graefes Arch Clin Exp Ophthalmol. 2005;243(8):748-753. doi:10.1007/s00417-004-1085-6

17. McElnea E, Stephenson K, Gilmore S, O’Keefe M, Keegan D. Paediatric retinal detachment: aetiology, characteristics and outcomes. Int J Ophthalmol. 2018;11(2):262-266. doi:10.18240/ ijo.2018.02.14

18. Wenick AS, Barañano DE. Evaluation and management of pediatric rhegmatogenous retinal detachment. Saudi J Ophthalmol. 2012;26 (3):255-263. doi:10.1016/j.sjopt.2012.04.005

19. Kocaoglan H, Unlü N, Acar MA, Sargin M, Aslan BS, Duman S. The efficacy of conventional rhegmatogenous retinal detachment surgery in the pediatric population. $J$ Pediatr Ophthalmol Strabismus. 2003;40(1):4-5. doi:10.3928/0191-3913-20030101-03

20. Soheilian M, Ramezani A, Malihi M, et al. Clinical features and surgical outcomes of pediatric rhegmatogenous retinal detachment. Retina. 2009;29(4):545-551. doi:10.1097/IAE.0b013e318194fd1a

21. AL-Zaaidi S, AL-Rashaed S, AL-Harthi E, AL-Kahtani E, Abu ElAsrar A. Rhegmatogenous retinal detachment in children 16 years of age or younger. Clin Ophthalmol. 2013;7:1001-1014. doi:10.2147/ OPTH.S40056

22. Orlin A, Hewing NJ, Nissen M, et al. Pars plana vitrectomy compared with pars plana vitrectomy combined with scleral buckle in the primary management of noncomplex rhegmatogenous retinal detachment. Retina. 2014;34(6):1069-1075. doi:10.1097/ IAE.0000000000000050

23. Alexander P, Ang A, Poulson A, et al. Scleral buckling com- bined with vitrectomy for the management of rhegmatogenous retinal detachment associated with inferior retinal breaks. Eye (Lond). 2008;22(2):200-203. doi:10.1038/sj.eye.6702555
24. Kinori M, Moisseiev E, Shoshany N, et al. Comparison of pars plana vitrectomy with and without scleral buckle for the repair of primary rhegmatogenous retinal detachment. Am J Ophthalmol. 2011;152 (2):291-297.e2. doi:10.1016/j.ajo.2011.01.049

25. Weichel ED, Martidis A, Fineman MS. Pars plana vitrectomy versus combined pars plana vitrectomy-scleral buckle for pri- mary repair of pseudophakic retinal detachment. Ophthalmology. 2006;113 (11):2033-2040. doi:10.1016/j.ophtha.2006.05.038

26. Holladay JT. Proper method for calculating average visual acuity. $J$ Refract Surg. 1997;13(4):388-391. doi:10.3928/1081-597X19970701-16

27. Storey P, Alshareef R, Khuthaila M, et al. Pars plana vitrectomy and scleral buckle versus pars plana vitrectomy alone for patients with rhegmatogenous retinal detachment at high risk for proliferative vitreoretinopathy. Retina. 2014;34(10):1945-1951. doi:10.1097/ IAE.0000000000000216

28. Verbraeken H, Ryckaert S, De Meunynck C. Pars plana vitrectomy in aphakic and pseudophakic retinal detachment. Graefes Arch Clin Exp Ophthalmol. 1986;224(3):203-204. doi:10.1007/BF02143054

29. Gartry DS, Chignell AH, Franks WA, Wong D. Pars plana vitrectomy for the treatment of rhegmatogenous retinal detachment uncomplicated by advanced proliferative vitreoretinopathy. $\mathrm{Br} J$ Ophthalmol. 1993;77(4):199-203. doi:10.1136/bjo.77.4.199

30. Campo RV, Sipperley JO, Sneed SR, et al. Pars plana vitrectomy without scleral buckle for pseudophakic retinal detachments. Ophthalmology. 1999;106(9):1811-1815. discussion 1816. doi:10.1016/S0161-6420(99)90353-6

31. Sindal MD, Gondhale HP, Srivastav K. Clinical profile and outcomes of rhegmatogenous retinal detachment related to trauma in pediatric population. CJO. 2020.

32. Sarrazin L, Averbukh E, Halpert M, et al. Traumatic pediatric retinal detachment: a comparison between open and closed globe injuries. Am J Ophthalmol. 2004;137(6):1042-1049. doi:10.1016/j. ajo.2004.01.011
Clinical Ophthalmology

\section{Publish your work in this journal}

Clinical Ophthalmology is an international, peer-reviewed journal covering all subspecialties within ophthalmology. Key topics include: Optometry; Visual science; Pharmacology and drug therapy in eye diseases; Basic Sciences; Primary and Secondary eye care; Patient Safety and Quality of Care Improvements. This journal is indexed on PubMed
Dovepress

Central and CAS, and is the official journal of The Society of Clinical Ophthalmology (SCO). The manuscript management system is completely online and includes a very quick and fair peer-review system, which is all easy to use. Visit http://www.dovepress.com/ testimonials.php to read real quotes from published authors. 